\title{
TERAPIA COGNITIVO COMPORTAMENTAL E TERAPIA DO ESQUEMA:UMA FAMILIARIZAÇÃO FRENTE A SAÚDE COLETIVA
}

\author{
Luiza Bastiani Soares'; Márcia Elisa Jager²
}

\section{RESUMO}

Objetiva-se descrever as vivencias de um estágio acadêmico, realizado no ambulatório do Hospital Casa de Saúde, em que a prática de atendimento psicológico efetuou-se no campo de estudo e atuação da Psicologia em um conceito amplo de saúde, com o individuo no centro de suas relações sociais, econômicas, politicas, ambientais e biológicas; juntamente de um aprimoramento do conhecimento sobre a articulação da Psicologia com outras áreas de conhecimento, para que fosse possível aprimorar e expandir aptidões técnicas, éticas e humanitárias na atenção à saúde. Utilizou-se como referencial teórico abordado, assim como a teoria utilizada nas práticas realizadas, como atendimentos clínicos, intervenções breves (acolhimentos), atividades grupais, reuniões e atividades cotidianas no serviço e com a equipe local: a Terapia Cognitivo Comportamental, com abordagem principal embasada na Terapia do Esquema. Assim, concluiu-se a elaboração de discussões pertinentes ao campo de atuação em prevenção e promoção da saúde, em que agregou ao funcionamento do serviço e o engajamento dos pacientes, tal qual a proximidade entre as técnicas e teorias empregadas.

Palavras-chave: Estágio; Hospital; Terapia Cognitivo Comportamental.

Eixo Temático: Atenção Integral e Promoção à Saúde (AIPS)

\section{INTRODUÇÃO}

O presente trabalho trata-se do relatório parcial de estágio Específico III - com a ênfase escolhida em prevenção e promoção da saúde - sendo uma disciplina do nono semestre do curso de Psicologia da Universidade Franciscana, em que foi realizada a prática de atendimento psicológico no campo de estudo e atuação da Psicologia em um conceito mais amplo de saúde, com o indivíduo no centro de todas as suas vivências.

Ao saber que a prática psicológica tem crescido cada vez mais estudos sobre análise e desenvolvimento do sujeito amplificaram-se; com o avanço da psicologia, as técnicas e instrumentos utilizados na análise são capazes de entender os fenômenos psicológicos e suas causas, e, para que a psicoterapia seja efetiva 0 psicólogo interpreta e explora as informações obtidas e observadas durante todo o processo de tratamento. A Terapia Cognitiva Comportamental (TCC) mostrou-se de

\footnotetext{
${ }^{1}$ Autor/Apresentador - Universidade Franciscana- UFN. luiza.bastiani@ufn.edu.br

2 Professora orientadora - Universidade Franciscana- UFN.marcia.jager@ufn.edu.br
} 
suma importância neste aspecto, por utilizar de modelos que enriquecem e propiciam o desenvolver do indivíduo; porém esta terapia com o passar dos anos, apresentou algumas limitações - segundo investigações de Jeffrey Young - para tratar de pacientes refratários e transtornos mais crônicos, de personalidade, pois os pacientes acometidos pelos mesmos, não dão retornos positivos suficientes ao tratamento, tais quais se encaixam a contínua inaptidão de identificar problemas, a falta de motivação para efetuar deveres e trabalhar técnicas de autocontrole, entre outros (CAZASSA et al., 2008).

Assim destaca-se o viés Cognitivo Comportamental enfocado na Terapia do Esquema como muito eficiente para que se tenha amplo acesso à realidade do paciente e a um bom tratamento. Em suma, para além do campo propriamente clínico, nos serviços de saúde também vê-se esta linha como muito efetiva; e a Psicologia possui como foco destes serviços complementar e integrar a rede de saúde mental dos municípios, ao dispor tratamento/atendimento clínico de uma maneira integrada com a rede básica de saúde, local em que é percebido a maioria das necessidades pelo serviço. Nestes locais, o trabalho do psicólogo difere-se, pois existem muitas mudanças, como a quantidade e tipos de demandas, a durabilidade dos atendimentos, sua frequência, o ambiente físico em que dispõe-se para o trabalho, os recursos, e o acompanhar do tratamento em sua multidisciplinaridade como um todo (SILVA et al., 2011). Destaca-se:

$\mathrm{Na}$ rede pública, a utilização de intervenções cognitivo-comportamentais ocorrem mediante adaptações e aplicações criativas, procurando respeitar as possibilidades existentes e todas as características do contexto público, como: falta de recursos, número elevado da demanda, tempo das sessões, fatores estes que caracterizam um desafio para a atuação do psicólogo, mas que não impossibilita o trabalho, tornando-o, assim, uma realidade possível. [...] Enfatiza-se a importância do trabalho interdisciplinar como forma de garantir a efetividade da proposta terapêutica. Essa possibilidade do diálogo com outros profissionais envolvidos no tratamento corresponde a uma das principais estratégias utilizadas e consideradas no setor público, onde torna-se significativo refletir sobre a interdisciplinaridade como uma via para a abertura do diálogo com a rede de atendimento(SILVA et al., 2011).

Utilizou-se durante a prática de estágio de métodos de análise e atividades clínicas dentro do contexto cognitivo comportamental, pautados nas demandas trazidas pelos usuários do serviço e do próprio serviço, possuindo início, meio e fim; com o intuito de compreender o funcionamento psicológico do sujeito e suas demandas através de técnicas, tal como proporcionar uma melhoria e agregação ao local de estágio junto da equipe multidisciplinar que lá atua; com a finalidade de proporcionar com que o resultado da atuação do estagiário na prevenção e promoção da saúde fosse positivo.

O objetivo deste relatório é descrever a experiência acadêmica de uma prática de estágio em prevenção e promoção da saúde realizada no Ambulatório do Hospital Casa de Saúde. Esta prática está vinculada à prática supervisionada do Estágio Específico III, do curso de Psicologia da Universidade Franciscana e ocorreu de forma individual. Este estágio tem como objetivo geral propor o exercício da prática profissional alicerçada num conceito ampliado de saúde, que compreende uma visão integral e contextualizada do ser humano em suas relações sociais, econômicas, políticas, ambientais e biológicas. Essa ênfase pressupõe, ainda, a 
articulação entre saberes da psicologia com outras áreas do conhecimento, de maneira a desenvolver competências técnicas, éticas e de humanização na atenção à saúde, voltadas para assistência, prevenção e promoção de saúde. Inclui temáticas como: saúde mental, atenção primária à saúde, sistema jurídico, modelos de atenção e organização dos serviços de saúde, epidemiologia e princípios do Sistema Único de Saúde (SUS).

\section{METODOLOGIA}

O trabalho foi embasado a partir de relatos de experiencia acerca do Estágio Específico III, realizado no Ambulátorio do Hospital Casa de Saúde. Com seu periodo mínimo de duração de estágio de um ano letivo (que continua no Especifico IV). Sua carga horária total semestral é de 220 horas, distribuídas em 08 horas/aula semanais de prática e 02 horas/aula semanais de supervisão. A carga horária semestral de prática equivale a 180 horas/aula nas quais são desenvolvidas a prática no local, elaboração de plano de estágio, elaboração de diários de bordo semanais, o estudo de textos indicados pela professora, a participação em eventos / lives / grupos de estudos, participação em supervisão coletiva e elaboração de relatório final de estágio. A carga horária semestral de supervisões acadêmicas equivale a 40 horas/aula.

O estágio ocorreu do período de março até julho de 2021, totalizando 235 horas de prática. As supervisões acadêmicas ocorreram semanalmente, de forma síncrona, via Teams. Como forma de aproveitar o espaço de supervisão como um momento coletivo de aprendizagem, elas foram realizadas em grupo. Para cada supervisão foram elaborados diários de bordo compartilhados com a professora supervisora, via google drive.

\section{RESULTADOS E DISCUSSÕES}

As práticas realizadas no Hospital Casa de Saúde (funcionais de segunda a sexta, das $8 \mathrm{~h}$ às $17 \mathrm{~h}$ ) tanto no campo da psicologia quanto dos demais profissionais e estagiários atuantes no serviço, focam-se em atender com empatia, compreensão e domínio de seu campo de atuação os usuários que procuram o serviço, que por ser exclusivamente SUS, o público-alvo torna-se amplo e diversificado, perpassando por todas as faixas etárias, etnias, escolaridade, e gênero e, por consequência, demandas. Os usuários que vão ao serviço são encaminhados pela secretaria de saúde do município, em especial os encaminhamentos para atendimento psicológico vêm dos profissionais que atendem no ambulatório, no hospital e na UPA. No local há diversas áreas profissionais atuantes, todas com seus respectivos estagiários (todos alunos UFN), tais quais: Anestesiologia - Equipe CLASM; Bucomaxilofacial 3 odontólogos; Cirurgia Geral - 2 médicos; Cirurgia Pediátrica - 1 médico; Cir. Plástica - 1 médico; Clínica da Dor - 1 médico; Ginecologia - 4 médicos; Fonoaudiologia - 2 fonoaudiólogos; Nutrição - 1 nutricionista; Otorrinolaringologista - 3 médicos; Pediatria - 3 médicos; Proctologia - 1 médico; Psicologia - 1 psicóloga; Psiquiatria - 4 médicos; Puerpério - 2 médicos; Pré-natal -2 médicos; Urologia - 3 médicos; Vascular - 3 médicos; Cardiologia - 4 médicos; Dermatologia - 2 médicos; Endocrinologia - 2 médicos; Gastroenterologia - 3 médicos; 
Hematologia - 1 médico; Nefrologia - 2 médicos; Neurologia - 1 médico; Ortopedia 2 médicos; Pneumologia - 3 médicos + espirometria; Reumatologia -2 médicos. As consultas com os mesmos dividem-se em uma primeira consulta/atendimento (primeiras consultas agendadas via regulação pela $4^{\circ}$ Coordenadoria de SaúdeSISREG), seguido de um retorno para exames e pós operatório, que são agendados de acordo com a agenda dos profissionais responsáveis.

O caráter cuidador e integralizador do hospital quando trata-se da busca e oferta de atenção à saúde pode ser considerado de dois vieses, um deles como o desenvolver do trabalho dentro do hospital, e o outro a partir do hospital, sendo a articulação do hospital com demais serviços de prevenção e promoção da saúde. No interior do hospital estas funções dependem do conjunto do trabalho de diversos profissionais, em que o fruto desse conjunto será o tratamento do paciente, união parcial do debruçamento com que cada profissional cuidará do sujeito, um complementando o outro. Dessa forma, uma união de saberes, ética, estudos, e rotinas compreendem o cuidado - promoção e prevenção - em saúde, e a maneira com que estes fatores se articulam entre os profissionais determinam melhor ou pior integralidade à saúde realizada. Do mesmo modo, a integralidade sobre o cuidado somente é alcançada quando em rede, por transpassar por vários serviços de saúde, em que cada um dispõe de métodos e ciências diferentes, e por isso o hospital pode ser percebido como uma ponte para que o paciente alcance o que precisa; a exemplo o vínculo com a rede de atenção básica, que facilita acesso a tratamentos e encaminhamentos, que faz possível com que acolhimentos e acompanhamentos sejam feitos (FEUERWERKER et al., 2006).

Assim, a aptidão do hospital em integrar suas realizações e alcance de conhecimentos com as tecnologias elaboradas em outros serviços, o foco nas relações entre público e privado, a autonomia, tratados de gestão, valorizam novos meios de estímulo frente a recursos humanos, também a humanização para com 0 paciente e seus direitos, as relações trabalhistas, e a atribuição e importância do Estado no fornecer de serviços de saúde, destacam-se como pontos relevantes da saúde coletiva nesse meio hospitalar (FREIRE, 2002).

\section{Psicologia na Prevenção e Promoção da Saúde}

Frente às demais práticas comuns ao contexto da prevenção e promoção da saúde apoiado à saúde coletiva, as principais práticas do psicólogo se dão no âmbito do Sistema Único de

Saúde, transpassando o modelo da clínica individual e com enfoque nas ações coletivas, tal como o planejar da administração/gestão do trabalho, estar consciente sobre as necessidades do território, dos artifícios comunitários e públicos, atividades com a comunidade local e a intersetorialidade das mesmas, o empenho no exercício de gerar rendas e redes de apoio, ampliando o trabalho em grupo quando possível para abordar temas de saúde recorrentes como HIV, AIDS, câncer, padrões de comportamento, entre outros a depender da demanda dos participantes; e acolhimento do usuário (exercendo aproximação e inclusão deste no serviço por meio da escuta e da atenção, independente do grau de gravidade sobre o motivo da sua procura, com compreensão e empatia) (PIRES et al., 2009).

Desse modo, após o inicio do Sistema Único de Saúde (SUS) no Brasil, em 1988, algumas transformações nas medidas de auxílio à saúde aconteceram, em 
especial a saúde mental, onde até os dias de hoje predomina o empenho a desinstitucionalização de pacientes com transtornos psiquiátricos, onde o foco está em entender os pacientes e seus perfis, para que seja possível cada vez uma melhor caracterização e obtenção de dados epidemiológicos e em decorrência, melhoria nos serviços oferecidos e intervenções possíveis (REIS et al., 2013).

A respeito do trabalho do psicólogo nesse contexto, para além da saúde mental, e expandindo para o âmbito de promoção da saúde e prevenção de adoecimentos, visto em suma na atenção básica, que tem sua atuação dentro do Sistema Único de Saúde (SUS), ele abrange a organização e disposição de serviços da área da saúde, entre eles a prevenção de enfermidades, vigilância epidemiológica e sanitária, proteção e melhora de danos, e práticas de promoção da saúde. Como evidenciado em estudos de Santos et al. (2010 apud BRASIL, 2007):

Entre as ações [...] destaca-se a Política Nacional de Promoção da Saúde (PNPS), que prevê, dentre outras, estratégias de articulação transversais que procurem a equidade, a participação e o controle social na gestão das políticas pública, por meio, preferencialmente, das unidades básicas de saúde (UBS) que operam sob a Estratégia de Saúde da Família (ESF) (SANTOS et al. 2010 apud BRASIL, 2007).

As ações oferecidas buscam tornar o sujeito-usuário como hábil para reger sua vida, e enfrentar - com ajuda apropriada - as desavenças que possam surgir; para isso, trabalha-se condutas em que o sistema é reorganizado, e o ambiente em que as participações acontecem, juntamente do controle da saúde da população, é ampliado. As medidas de atendimento e tratamento olham para o individuo e também para seu núcleo familiar, seu ganho, seu trabalho, recursos alimentícios, e seus momentos de relaxamento; resultando em um self e autonomia mais fortalecido do paciente e do coletivo em que vive, e também resoluções e visões compassivas para adversidades que fazem parte desse mesmo coletivo (SANTOS et al. 2010).

No âmbito da Atenção Básica, a Estratégia de Saúde da Família (ESF) vêm assumindo uma posição importante, abraçando a proteção e prevenção da saúde, incluindo diagnóstico, intervenções, prevenir doenças, a manutenção e reabilitação; e a atenção primária, igualmente importante, porém mais restrita, foca-se na saúde do coletivo em ênfase de prevenção e promoção. Frente a estes e aos demais serviços que lhes são vinculados, o trabalho interdisciplinar com as equipes e 0 psicólogo são meios de efetivar as ações oferecidas, e ampliar o conhecimento, em destaque o psicólogo contribui ao poder analisar e compreender o sujeito, em sua integralidade, na família, e no social em que vive; se deve a isto a importância do trabalho entre as equipes interdisciplinares e tratamentos intersetoriais.

A conexão da Atenção Básica à saúde mental também é um fator necessário e que busca crescimento constante, uma vez que a melhora e ampliação dos serviços para os usuários juntamente da continuidade do tratamento dependem desta conexão. Em suma, para que o SUS se fortaleça cada vez mais, a Saúde da Família é uma ferramenta admirável, mas é necessário prover e depositar recursos humanos, a fim de melhorar a atenção básica, junto dos profissionais praticando interdisciplinaridade e suas equipes (BOING et al., 2010).

Estas vinculações, práticas, e possibilidades, por meio do SUS, encontram-se na RAPS (Rede de Atenção Psicossocial), e visam a expansão para a população dos serviços de atenção psicossocial, a promoção de bons relacionamentos entre 
usuários acometidos por transtornos mentais, e/ou de usuários dependentes e fragilizados por uso de crack, álcool e demais drogas, e seus familiares; e o cuidado através do acolhimento, e acompanhamento, junto da atenção dedicada às urgências. A RAPS possui articulações por meio de Unidades Básicas de Saúde (UBS), Núcleos de Apoio à Saúde da Família (NASF), Consultórios na Rua, Centros de Convivência, Centros de Atenção Psicossocial em suas diferentes modalidades (CAPS), Atenção de Urgência e Emergência, Unidades de Acolhimento, Serviços de Atenção em Regime Residencial, Leitos de Saúde Mental, Álcool e Outras Drogas em Hospitais Gerais, e Serviços Residenciais Terapêuticos (CRUSOÉ et al., 2017).

Nessa perspectiva, ainda seguindo o estudo do autor citado anteriormente, 0 trabalho do psicólogo na atenção básica possui viabilidades para melhor compreender acerca dos dilemas humanos, que também situa o próprio indivíduo que vai até o serviço à ter uma nova dimensão de entendimento sobre si.

Ainda, ressalta-se como igualmente importante as atividades grupais destes usuários, uma vez que impactam no coletivo em geral; tais quais os locais em que os profissionais praticam acolhimento, sejam públicos ou particulares, mas que visam a saúde em comum, outrossim compreende-se que o trabalho do psicólogo é rico de empatia e compreensão, e que a cada dia ganha mais espaço e valor em meio ao egocentrismo dos dias atuais. Logo, o trabalho individual com o paciente, ou grupal, em atendimento breve ou continuado, possui a potência para gerar novas perspectivas de experiências e condutas, consigo, com o mundo, e com o outro, partindo da oportunidade de trocar conhecimentos com outrem, de encarar o que é diferente, e de saber e poder viver com saúde no coletivo social (SANTOS et al. 2010).

\section{Terapia Cognitivo Comportamental e vinculação à Terapia do Esquema}

Para as práticas clínicas realizadas no cotidiano do serviço utilizou-se o viés teórico da Terapia Cognitivo-Comportamental, especialmente aquele vinculado à Terapia do Esquema.

Terapia Cognitivo Comportamental (TCC), que originou-se a partir do neobehaviorismo e análise do comportamento, possuiu desde sua origem uma forma lógica e o apoio científico para que realizem-se estudos e análises de como o comportamento se rege, com a criação também de paradigmas; assim estabeleceuse o objetivo de através de observações, prognósticos, e mudanças no comportamento, proporcionar saúde mental aos indivíduos, que recebeu o nome de terapia de terceira onda, devido a ordem com que foi criada frente às demais terapias existentes na época.

A criação da Terapia Cognitivo Comportamental (TCC), em sua primeira geração, surgiu a partir de um movimento contra as ideias clínicas que predominavam no início do século $X X$, por serem pouco comprovadas cientificamente e apresentarem poucos resultados efetivos. As gerações que vieram após, a segunda e a terceira, referiam-se a técnicas da terapia cognitivo comportamental, com trabalhos e fins em comum; assim as Terapias de terceira geração, ganharam seu início desde 1990 a partir das gerações prévias, mas com a apresentação de resultados cada vez melhores.Técnicas e intervenções como aceitação, mindfulness, e defusão cognitiva tangem estratégias de modificações desta abordagem. 
Entre as principais abordagens da terceira onda estão: Terapia de Aceitação e Compromisso, Terapia Comportamental Dialética, Ativação Comportamental, Terapia Cognitivo baseada em Mindfulness, Programa de Redução de Estresse Baseada em Mindfulness, Terapia Comportamental Integrativa de Casais, Psicoterapia Analítico Funcional e Terapia Focada na Compaixão (SANTOS et al., 2015).

Dessa forma, com a finalidade de solucionar as limitações reconhecidas, concretizou-se a Terapia Focada em Esquemas (TE), cujo principal pioneiro foi Jeffrey $\mathrm{E}$. Young, que aperfeiçoou técnicas psicoterápicas, advindas do padrão cognitivo de Aaron Beck, ao trabalhar na cognição o Esquema Inicial Desadaptativo (EID), que são alicerces da personalidade que se desenvolvem ao longo da vida do indivíduo e liga-se a numerosas patologias, que perpassam a maneira com que 0 sujeito interpreta e interage com suas vivências.

Uma vez que os EIDs são reconhecidos, podem ser trabalhados pelo terapeuta com a utilização de técnicas singulares, próprias para que os sintomas do paciente se atenuem juntamente de suas distorções cognitivas. Logo, quando fatores da personalidade ocasionam impasses de habituação e causam padecimentos ao paciente e/ou as pessoas de seu convívio, suspeita-se de algum transtorno de personalidade; os sujeitos acometidos deste transtorno usualmente manifestam esquemas desadaptativos, e sua cognição trabalha a partir de distorções cognitivas, como estudado por Beck (apud YOUNG et al., 2008).

Por esta razão, em concordância com estudos de Soares (2010), a Terapia dos Esquemas (TE), ao aceitar o sujeito em suas dificuldades, utilizar técnicas e manejo para que os comportamentos inadequados diminuam e se ajustem alterar a regulação afetiva, a compreensão do estresse e a capacidade de manter relacionamentos interpessoais, é a mais indicada para tratar os pacientes acometidos por transtornos de personalidade, e apresenta altos níveis de efetividade. Segundo Wainer et al. (2016):

A TE expõe todo um sistema explicativo da personalidade - muito embora se possa perceber que os trabalhos de Young não tivessem como premissa esse objetivo de uma teoria geral da personalidade dentro do cognitivismo, e sim o de gerar um novo conjunto de técnicas e conceitos para lidar com esses pacientes graves. Mesmo que de forma indireta, a TE atingiu uma formulação nunca antes obtida dos fatores envolvidos na gênese da personalidade, bem como dos processos mentais mantenedores de sua homeostase (WAINER et al. 2016, p.16).

\section{Prática e Teoria}

Ao longo da prática de estágio, três pacientes-usuários foram atendidos, no qual os atendimentos ganharam continuidade e encaminhamentos e um paciente foi desligado por motivo de que foi marcado uma consulta ( a primeira consulta) para atendimento psicológico e o mesmo não compareceu nem comunicou sua falta ao serviço.

Todos os usuários eram atendidos no mesmo dia da semana (um dia da semana foi separado para prática de estágio) a fim de que houvesse um melhor aproveitamento do tempo em campo de estágio e de organização da estagiária, prática que iniciava-se às $8 \mathrm{~h}$ e terminava às $17 \mathrm{~h}$ cumprindo as $8 \mathrm{~h}$ semanais exigidas pela cadeira de Estágio Específico III; entre os atendimentos e nos intervalos 
efetuou-se a leitura de livros, prontuários dos pacientes atendidos em questão, e feita a evolução clínica dos mesmos no sistema online do ambulatório (que era feita para cada paciente individualmente após todos os atendimentos). Durante os demais dias da semana e ao longo dos meses, eram praticadas também supervisão de estágio, leitura de texto, elaboração de diário de bordo (um para cada paciente atendido), e atividades complementares, como participação em seminários e eventos online, cursos profissionalizantes, e elaboração de documentos sobre o próprio serviço em que se atuou, a exemplo um fluxograma explicando sobre o funcionamento do ambulatório do Hospital cada de Saúde.

A respeito das leituras e elaboração de escritos tal qual os diários de bordo, destaca-se que leitura e escrita influenciam tanto no compreender do presente e de situações singulares, quanto nos impactos destas ações para construções de vida futuras em seus mais variados âmbitos, como no estudo de Zacarias et al. (2017):

[...] a leitura é ferramenta imprescindível para o indivíduo se inserir na sociedade atual devido às exigências cobradas pelo mundo contemporâneo. Isso se deve ao fato que, uma vez que aquele que está mais apto a lidar com essa competência, muito possivelmente, ocupará, na sociedade, um lugar de maior prestígio. Referente a escrita, mesmo que o trabalho não seja sobre escrita, é relevante dizer, que por meio da escrita que os educandos desenvolverão suas ideias, pensamentos e do que entendem sobre "visão de mundo". [...] Mas, para que haja essas habilidades é necessário e indispensável que a leitura seja se torne um "gosto" para que, assim, conduza o indivíduo a um processo constante de aprendizagem por meio da leitura [...](ZACARIAS et al., 2017).

Em suma, criou-se um fluxograma sobre o funcionamento do ambulatório como um todo, após uma reunião com a enfermeira chefe do local, a fim de poder visualizar e compreender de forma mais ampla as possibilidades e funcionalidades do local, como também expor a colegas estudantes e profissionais acerca de todos os processos que o serviço dispõe. Segundo Navarro (2018) o fluxograma é importante uma vez que sua elaboração coopera para:

[...] permite visualizar de maneira integral e sintética certos processos e ações da empresa. Dessa forma, é possível entender como eles funcionam e identificar falhas e mudanças necessárias com maior facilidade. Ele também é muito utilizado como ferramenta de aprendizado para treinar novos funcionários ou introduzir inovações nas instituições (NAVARRO 2018).

Outrossim, as leituras, elaborações, e escritos possibilitaram um maior e melhor entendimento acerca da Terapia Cognitivo Comportamental e da Terapia do Esquema, as quais pautaram a escuta, as intervenções durante os atendimentos, e o olhar sobre o sujeito.

O estágio se iniciou com a estagiária entrando em contato telefônico com alguns dos usuários que tinham fichas no serviço (ou seja, foram encaminhados para o serviço de psicologia do ambulatório), para saber se havia interesse da parte deles em iniciar atendimento psicológico, com os quatro usuários que foram contatados, todos demonstraram interesse e foi marcado atendimento para os mesmos, um desses pacientes não compareceu ao serviço no dia combinado do atendimento, nem comunicou a falta, posteriormente a estagiária tentou contato telefônico, no qual o paciente não atendeu, então foi desligado do serviço por falta de frequência e 
contato. O segundo usuário compareceu ao serviço desde o primeiro atendimento agendado, D (de 47 anos, sexo masculino), dia 05/05/2021, e como combinado durante os atendimentos, suas sessões teriam intervalo de uma semana entre uma e outra, totalizando 5 atendimentos totais ao final do estágio, faltou apenas uma vez e quando ocorreu comunicou ao serviço; foi encaminhado pelo psiquiatra do ambulatório para atendimento psicológico pois desde o início da pandemia começou a apresentar crises, em que sentia palpitações, sensação de quase morte, sudorese, e durante as mesmas se sentia incapaz de fazer qualquer coisa, até mesmo raciocinar; crises que eram despertadas frente a quaisquer notícias relacionadas ao Covid-19. Para atender as demandas trazidas trabalhou-se exercícios de RPD (Registro de Pensamentos Disfuncionais) que é técnica da terapia cognitivocomportamental com o intuito de facilitar para o paciente identificar e analisar, junto do psicólogo, e de maneira mais consciente os pensamentos, emoções e comportamentos durante os momentos que lhe causam maior dificuldade (e que são motivos de sua procura pelo serviço/encaminhamento) auxiliando o sujeito a idealizar respostas mais adaptativas frente às suas cognições negativas e assim ter uma qualidade de vida maior e mais funcional, além de ampliar sua compreensão sobre seu funcionamento (CREPALDI, 2018). Já no segundo atendimento o usuário não apresentou mais crises, e até o quinto (e último) atendimento pontuou várias vezes em seu discurso o quanto estava melhor, sem crises, e compreendendo seu modo de pensar, o que era certo em sua concepção, e o que não era, assim como as consequências de seus atos; passou a ponderar suas reações e atitudes - o que Ihe trazia benefícios para seu relacionamento com os demais membros de sua família e sua forma de ver o mundo. O objetivo de seu tratamento era atender a demanda a respeito das crises, a qual foi atendida e tratada, e ao final o usuário foi encaminhado para outro serviço de atendimento psicológico do município, de psicoterapia, para que possa abranger suas outras questões cotidianas e não urgentes que foram trazidas à tona nos últimos atendimentos.

Um terceiro paciente iniciou os atendimentos psicológicos, L (20 anos, sexo feminino), dia 05/05, e totalizaram dois atendimentos, em sequencia teve duas faltas, a primeira não justificada, e na segunda vez, o proprio paciente se dirigiu ao serviço para justificar a falta e alegar que gostaria muito de continuar em atendimento psicoterápico, mas que por questões pessoais, necessitaria remarcar dia e horario, por esta razão a paciente foi transferida para que outro estagiário a atendesse, que tivesse disponibilidade de horários que se encaixassem com os dela. Fora encaminhada pela psiquiatria (faz uso de remédio para tratar a depressão diagnosticada) para a psicologia devido a seu medo extremo de engravidar, e nos seus dois primeiros atendimentos relatou sua história de vida, familiar, onde foi possível compreender o motivo de sua demanda. Observou-se circunstâncias de desenvolvimento emocional disfuncional, além da depressão, e foi pensado como tratamento inicial realizar uma psicoeducação acerca do transtorno e do modelo cognitivo, seguido da identificação das crenças e pensamentos distorcidos (ex: seta descendente)(MARTINS, 2020), ensinar a paciente sobre habilidades sociais, para que a auxiliasse nas suas decisões futuras e em seus comportamentos, juntamente de tarefas de casa; os tratamentos descritos não foram completados devido a transferência de estagiários que houve, mas foi possível realizar uma psicoeducação inicial breve no segundo atendimento. Observa-se uma visão do transtorno 
depressivo pela autora Martins (2020) na abordagem referida:

Para a TCC o sujeito com depressão possui uma tríade cognitiva negativa, isto é, a visão de si, do mundo e do futuro é distorcida. Notam-se diversas distorções cognitivas, ou seja, erros sistemáticos na interpretação de si e do mundo. Assim, um dos focos da terapia é auxiliar o cliente a desenvolver uma visão menos disfuncional, mais verdadeira da realidade Martins (2020).

O quarto paciente iniciou os atendimentos psicológicos, D (9 anos, sexo masculino), no dia 12/05 e totalizaram-se seis atendimentos, faltou apenas uma vez e quando ocorreu comunicou ao serviço, foi ao atendimento pois um de seus irmãos foi emcaminhado pelo conselho tutelar para atendimento psicológico no ambulatório, e sua mãe preferiu que todos os irmãos também recebessem atendimento psicológico; o encaminhamento e necessidade se deu a partir de um conflito familiar, em que quase houve uma agressão de um adulto (padrasto) para com menor de idade, o menor de idade era um dos irmãos - o mais velho (são três irmãos), e os outros dois irmãos precensiaram a cena, a fim de ajudar os filhos a entenderem 0 que aconeceu, e a prevenir quaisquer trauma que pudesse vir desta experiencia, a mãe procurou atendimento da psicologia para todos no ambulatório. $O$ mais velho e o mais novo estão em atendimento com outras duas estagiárias do local. O paciente não apresentou demandas, objetivou-se então trabalhar sentimentos e pensamentos frente a situação presenciada, logo foram feitos muitos exercícios lúdicos, como desenhos, brincadeiras com bola, jogos (ex:dominó e quebra-cabeças), através dos quais o paciente mostrou-se sempre muito criativo, conversou desde o início sobre seus sentimentos, pensamentos e vontades, ainda conversou-se com a mãe em um primeiro atendimento, onde também não houve queixas/demandas. Ao final dos atendimentos de todos os irmãos haverá uma devolutiva em conjunto entre as três estagiárias que os atendem, para com a mãe, onde será comunicado e explicado todos os aspectos observados das crianças, assim como futuros encaminhamentos para psicoterapia conforme a mãe e seus filhos sentissem necessidade. O paciente em questão não apresentou traumas, medos, ou mágoas sobre a situação experienciada, e compreendeu o propósito de seus atendimentos desde o princípio, também criou uma relação terapêutica com a estagiária que foi de suma importância para que barreiras como a timidez inicial, e seus segredos fossem ultrapassados e compartilhados com a mesma; seu atendimento se finalizou em julho pelo mesmo ter demonstrado estar bem consigo e suas questões, seus familiares, e no ambiente em que vive. A respeito do trabalho com crianças para a Terapia CognitivoComportamental e suas vertentes, pode-se utilizar de técnicas como citadas por Lage (2020):

[...]psicólogo qualificado para essa modalidade pode lançar mão de recursos como desenhos, jogos e brincadeiras que ajudem a acessar o imaginário da criança. [...] a terapia cognitivo-comportamental para crianças tenta entender como os aspectos cognitivos podem originar transtornos emocionais e comportamentais. Por isso, o terapeuta tenta identificar quais são as dificuldades vivenciadas naquele momento pela criança; eventos importantes de sua infância; qual a percepção que o indivíduo tem de si mesmo e do outro. Igualmente, crenças, estratégias de recompensa e expectativas da família em direção a ela também têm relevância no tratamento (LAGE , 2020). 
Com isso, pode-se observar que quando o trabalho do psicólogo enquadra-se no nível de atenção ao social, permeado pelo SUS, há a necessidade de fornecer empoderamento para o usuário e para o coletivo, quando trata-se de conhecer sobre si, o território, suas demandas e pensar nos caminhos de cuidado que podem ser seguidos, tornando possível que mudanças positivas aconteçam em suas vidas.

Ao referir-se aos profissionais e estagiários, a mudança se inicia desde as primeiras trocas dentro do próprio espaço em que se atua, tanto com os usuários quanto com a equipe na qual divide suas funções. Assim, quando há a oportunidade de um graduando em psicologia fazer parte de espaços ligados ao setor público e a saúde coletiva, há também a chance de direcionar o olhar para aspectos do social, antes não tão concretos quanto na oportunidade de conhecer na prática produzindo um interesse crescente em trabalhar com enfoque nas políticas públicas, que pode ser na saúde ou outros campos.

\section{Considerações Éticas}

Através do Código de Ética Profissional do Psicólogo, onde a estagiária pautou sua prática embasada nos direitos humanos e seguindo o princípio: "toda profissão define-se a partir de um corpo de práticas que busca atender demandas sociais, norteado por elevados padrões técnicos e pela existência de normas éticas que garantam a adequada relação de cada profissional com seus pares e com a sociedade como um todo" $(2005$, p.5). A partir das demandas sociais as quais são férteis para o trabalho do psicólogo, o Código de Ética Profissional do Psicólogo procura contemplar e refletir a diversidade do exercício do psicólogo e os numerosos contextos, como por exemplo, os que esse Relatório Parcial de Estágio abrange: os processos de prevenção e promoção de saúde e a atuação no contexto ambulatorial.

Por fim, a prática de estágio remota em psicologia está ancorada no documento "Práticas de estágios remotos em Psicologia no contexto da pandemia da Covid-19", elaborado pelo Conselho Federal de Psicologia a partir da portaria MEC no 544, de 2020 e outros documentos importantes. O documento expõe várias possibilidades de práticas em psicologia de acordo com os processos de trabalho.

\section{CONCLUSÃo}

Os pontos aqui apresentados permitem comprovar a importância da atuação do psicólogo para além de um contexto clínico, para um contexto ampliado de saúde, colocando em prática várias atuações, como reuniões entre estagiários, reuniões com demais profissionais que atuam no mesmo serviço, contatos com outros serviços públicos de saúde, para mencionar alguns exemplos. Torna-se possível também notar o quanto as atividades realizadas dentro de um contexto de saúde, de atendimento ambulatorial, são importantes.

Apesar das dificuldades frente às práticas, por questões de frequência dos usuários, ou das próprias demandas, por tratar-se de atendimentos mais pontuais, e, por isso, se fazer necessário utilizar menos técnicas interventivas do que se usaria em atendimentos a longo prazo, constatou-se um fortalecimento frente a superação de um viés clínico tradicional, com ampliações reflexivas acerca de novos fazeres 
psicológicos, com um olhar mais estudioso e criativo, viabilizando o psicólogo enquanto pessoa e profissional a se deslocar de um lugar estabelecido historicamente para uma prática que é comprometida no social, por estar necessitada de auxílio e apoio devido ao número de demandas que só crescem, ou seja, somando a um novo fazer, a um atuar em ascensão.

Ao refletir sobre a continuidade desta atuação para o próximo semestre, surgem ideações de que concepções ainda mais ricas acerca da temática ambulatorial e hospitalar se formarão, como também novos vieses para emprego do conhecimento e aprimoramento sobre a Terapia Cognitivo Comportamental e Terapia do Esquema, tal como a prática das mesmas, que se configura como desejo primordial - poder praticar tratamentos nestas abordagens e perceber junto com o usuário sua melhora.

\section{REFERÊNCIAS}

BOING, Elisangela et al. O Psicólogo na atenção básica: uma incursão pelas políticas públicas de saúde Brasileiras. Psicologia: Ciência e Profissão, [s. I.], 2010. DOI 10.1590/S1414-98932010000300014. Disponível em:

https://www.scielo.br/scielo.php?script=sci_arttext\&pid=S1414-98932010000300014. CAZASSA, Milton José et al. Terapia focada em esquemas: conceituação e pesquisas. 2008. Disponível em: https://www.scielo.br/pdf/rpc/v35n5/a03v35n5.pdf. CONSELHO FEDERAL DE PSICOLOGIA. Práticas e estágios remotos em psicologia no contexto da pandemia da covid-19: recomendações. Recurso Eletrônico. 1 edição. Brasília. CFP, 2020. Disponível em https://site.cfp.org.br/publicacao/praticas-e-estagios-remotos-em-psicologia-nocontexto-da-pandemia-da-covid-19-recomendacoes/ CONSELHO FEDERAL DE PSICOLOGIA. Resolução CFP no 010, agosto de 2005. Aprova o Código de Ética Profissional do Psicólogo. 2005. Disponível em https://site.cfp.org.br/wp-content/uploads/2005/07/resolucao2005 10.pdf.

CREPALDI, Mariana. Por favor, não menospreze o RPD: Técnicas Cognitivas. In: CREPALDI, Mariana. Facilitah Desenvolvimento. [S. I.], 2018. Disponível em: https://facilitahdesenvolvimento.com.br/por-favor-nao-menospreze-o-rpd/.

CRUSOÉ, ANE CIBELE VILELA UMBURANAS et al. A atuação dos/as psicólogos/as em Centros de Atenção Psicossocial (CAPS): uma análise de relatos de experiências no Nordeste. Repositório Institucional Escola Bahiana de Medicina e Saúde Pública, [s. I.], 2017. Disponível em:

https://repositorio.bahiana.edu.br:8443/jspui/handle/bahiana/831.

FEUERWERKER, Laura Camargo Macruz et al. O hospital e a formação em saúde: desafios atuais. Ciência \& Saúde Coletiva, [s. l.], 2006. Disponível em: https://scielosp.org/article/csc/2007.v12n4/965-971/.

FREIRE, June Barreiros. A saude coletiva acerca-se do hospital: o caso do Hospital Publico Regional de Betim. 2002. 193p. Dissertação (mestrado) Universidade Estadual de Campinas, Faculdade de Ciências Médicas, Campinas, SP. Disponível em: http://www.repositorio.unicamp.br/handle/REPOSIP/311589 LAGE , Ana Paula. Terapia cognitivo-comportamental em criança: funciona mesmo?. In: Noeh. [S. I.], 2020. Disponível em: https://noeh.com.br/terapia-cognitivocomportamental/. 
MARTINS, Eliana. Como a Terapia Cognitivo-Comportamental trata a Depressão?. In: Centro de estudos em Terapia Cognitivo - Comportamental. [S. I.], 2020.

Disponível em: https://www.cetcc.com.br/blog/15/Como+a+Terapia+CognitivoComportamental+trata+a+Depress\%C3\%A30\%3F.

NAVARRO, Leonardo. A IMPORTÂNCIA DE FAZER O FLUXOGRAMA DE UMA EMPRESA. In: NAVARRO, Leonardo. IDEBRASIL. [S. I.], 2018. Disponível em: http://www.idebrasil.com.br/blog/a-importancia-de-fazer-o-fluxograma-de-umaempresa/.

PIRES, Ana Cláudia Tolentino et al. O psicólogo na saúde pública: formação e inserção profissional. Temas em Psicologia, [s. I.], 2009. Disponível em: http://pepsic.bvsalud.org/scielo.php?script=sci_arttext\&pid=S1413389X2009000100013.

REIS, Leonardo Naves dos et al. Perfil dos usuários com diagnóstico de transtornos de personalidade de um serviço de saúde mental. SMAD, Rev, Eletrônica Saúde Mental Álcool Drog., Ribeirão Preto, v. 9, 2013. Disponível em: http://pepsic.bvsalud.org/scielo.php?script=sci_arttext\&pid=S1806$69762013000200004 \& \operatorname{lng}=$ pt\&nrm=iso\&tlng=pt.

SANTOS , Keli Lopes et al. A atuação do psicólogo na promoção da saúde.

Psicologia: teoria e prática, São Paulo, 2010. Disponível em:

http://pepsic.bvsalud.org/scielo.php?script=sci_arttext\&pid=S1516-

36872010000100015.

SANTOS, Paola Lucena et al. TERAPIAS COMPORTAMENTAIS DE TERCEIRA GERAÇÃO: Guia para profissionais. Novo Hamburgo: Sinopsys Editora, 2015. ISBN 978-85-64468-46-7. Disponível em:

https://www.sinopsyseditora.com.br/upload/produtos_pdf/370.pdf.

SILVA, Shirley de Souza et al. A Terapia cognitivo-comportamental no ambulatório público: possibilidades e desafios. Revista Brasileira de Terapias Cognitivas, [s. I.], 2011. Disponível em: http://pepsic.bvsalud.org/scielo.php?script=sci_arttext\&pid=S180856872011000100008.

SOARES, Marcos Hirata. Estudos sobre transtornos de personalidade Antissocial e Borderline. Scielo, São Paulo, v. 23, 2010. DOI 10.1590/S010321002010000600021. Disponível em:

https://www.scielo.br/scielo.php?script=sci_arttext\&pid=S0103-

21002010000600021\&lang=en.

WAINER, Ricardo et al. Terapia Cognitiva Focada em Esquemas: Integração em Psicoterapia. Porto Alegre: Artmed, 2016. 239 p. ISBN 978-85-8271-257-3. YOUNG, Jeffrey E. et al. Terapia Do Esquema: Guia de técnicas cognitivocomportamentais inovadoras. Porto Alegre: Artmed, 2008. 368 p. ISBN 978-85-3631496-9.

YOUNG, J. KLOSKO, J.S.WEISHAAR, M.E. Terapia do Esquema: Guia de técnicas cognitivo-comportamentais. Porto Alegre: Artmed. 2018.

ZACARIAS, Ezequiel de Souza et al. A IMPORTÂNCIA DA LEITURA PARA O DESENVOLVIMENTO INTELECTUAL E SOCIAL DO INDIVÍDUO. Edoc-Ufam, [s. I.], 2017. Disponível em: https://edoc.ufam.edu.br/retrieve/7810f7c4-4c91-442a-a18baa5688bf9a71/TCC-Letras-2017-Arquivo.009.pdf. 